\title{
Analysis on the Spatio-Temporal Evolution and Influencing Factors of China's Grain Production
}

Shaoting Li ( $\sim$ brucelee0324@163.com )

Northwest A\&F University: Northwest Agriculture and Forestry University https://orcid.org/0000-00024108-6133

\section{Daojun Zhang}

Northwest A\&F University: Northwest Agriculture and Forestry University

Yuan Xie

Northwest A\&F University: Northwest Agriculture and Forestry University

Chao Yang

Northwest A\&F University: Northwest Agriculture and Forestry University

\section{Research Article}

Keywords: Grain production, Spatial heterogeneity, Geographically weighted regression, Influencing factor, Food security

Posted Date: November 11th, 2021

DOl: https://doi.org/10.21203/rs.3.rs-837674/v1

License: (c) (i) This work is licensed under a Creative Commons Attribution 4.0 International License. Read Full License

Version of Record: A version of this preprint was published at Environmental Science and Pollution Research on November 24th, 2021. See the published version at https://doi.org/10.1007/s11356-02117657-2. 
1 Analysis on the Spatio-temporal Evolution and Influencing Factors of China's

${ }^{a}$ College of Economics and Management, Northwest A\&F University, Yangling, 712100, China

${ }^{b}$ Center for Resource Economics and Environment Management, Northwest A\&F University,

$6 \quad$ Yangling, 712100, China

$7 \quad{ }^{*}$ Corresponding author: cugzdj@gmail.com (Zhang, D)

\section{Acknowledgments:}

9 This study benefited from joint financial support by the National Natural Science Foundation of China (No. 42071416), the Program of Shaanxi Provincial Natural Science Foundation (No. 2020JM-170), and China Postdoctoral Science Foundation (No.2017T100773). Great thanks to

12 the anonymous referees for their helpful suggestions and corrections. 


\section{ABSTRACT}

The rapid economic development and climate change have accelerated the changes in China's food production and have a potential impact on food security. In this paper, the grain sown area from 2001 to 2019 was selected to analyze the spatio-temporal evolution and driving factors of China's grain production through spatial autocorrelation analysis and geographically weighted regression. Our findings were as follows: (1) From the perspective of time characteristics, China's grain production from 2001 to 2019 experienced four stages: rapid decline, rapid growth, steady growth, and slow decline, although with an overall upward trend. (2) From the Influencing factor; Food security 


\section{Introduction}

Food security is the cornerstone of social development in China (Qi and Dang 2018). With $7 \%$ of the world's arable land, China has fed $1 / 5$ of the world's population and achieved remarkable results in grain production. However, in the process of urbanization, the relationship between humans and land became increasingly tense (Long and Qu 2018), the contradiction between agricultural development and ecological environment was prominent (Chen et al. 2017). What's more, the obstruction of factor flow between urban and rural areas and the transformation of farmers' livelihoods (Liu and Liu 2016; Qin 2010) also posed a significant threat to the grain production, seriously affecting national food security (Chen 2007). Therefore, studying the spatio-temporal evolution and influencing factors of China's grain production is of great importance to ensure food security.

Grain production has always been a hot topic for scholars. Studies showed that since the reform and opening up in 1978, China's total grain output had doubled, becoming the world's largest food producer (Jiao et al. 2018; Jiao et al. 2016). The total grain output increased by 65\% in the past 30 years (Niu et al. 2021), completely eliminating the social problem of hunger (Huang and Yang 2017). However, the increase of food yield was at the expense of the environment (Zhang et al. 2013). It was estimated that more than half of the arable land experienced varying degrees of degradation ( $\mathrm{Li}$ et al. 2011). The excessive use of pesticides and chemical fertilizers also led to serious non-point source pollution and soil acidification, which brings new challenges to food production (Guo et al. 2010; Wang et al. 2019a). Meanwhile, the spatial pattern of food production changed due to different policies and economic development models (Xu et al. 2013). The northward shift of the production center intensified the spatial mismatch among food production, arable land resources and hydrothermal conditions (Li et al. 2017). Zhang et al. (2021) found that China's grain production efficiency generally showed a downward trend from 2001 to 2017. Therefore, China urgently needs to transform its production 
model to protect natural resources and achieve sustainable development of food production (Liu and Chen 2007; Lu et al. 2015).

The grain production was affected by many factors. Some scholars explored the impact of subsidy policies on grain production, and the results showed that subsidy increased farmers' motivation to grow grain (Goodwin and Mishra 2005; Huang et al. 2013; Yi and McCarl 2018), expanding grain cultivation area (Huang and Ding 2016; Yi et al. 2015). In contrast, the transfer of agricultural labor force had a negative impact on food production. The shift of male youngadult workforce to urban areas made agricultural labor force aging and feminization (Zhao 1999), and the decline of human capital adversely affected food production (Rozelle et al. 1999). However, agricultural mechanization can make up for the loss of grain production caused by labor shortage ( $\mathrm{Ji}$ et al. 2017b). The reason was that use of agricultural machinery achieved large-scale operations in food production and improved food productivity (Yin and Wang 2017). Climate change was also an important factor affecting food production. Holst et al. (2013) believed that the increase of $1{ }^{\circ} \mathrm{C}$ in annual average temperature reduced China's grain output by $1.45 \%$, and that every $100 \mathrm{~mm}$ increase in total annual precipitation increased grain output by $1.31 \%$. In addition, the abnormal climate also led to the frequent occurrence of natural disasters such as drought, flood and hail (Du et al. 2015).

In summary, the existing studies mostly selected grain output to measure grain production. In fact, grain sown area is an important basis for grain production (Wang and Xiao 2013). Few scholars explored the spatio-temporal evolution characteristics of grain production from this perspective. In addition, the research on the influencing factors of grain production was mostly carried out by global model, which lacks spatial consideration and fails to reveal the spatial heterogeneity and dynamic evolutionary process of influencing factors. It was not conducive to formulating agricultural policies according to local conditions, coordinating national grain production and improving grain production capacity. Based on this, we selected the data of 
grain sown area in China from 2001-2019 to investigate the spatio-temporal evolution of grain production through spatial autocorrelation analysis. Geographically weighted regression was used to study the influencing factors to provide references and suggestions for stabilizing grain production and ensuring food security.

\section{Materials and methods}

\subsection{Study area}

China's terrain is high in the west and low in the east, with a three-step distribution. The unique geographical and climatic environment can meet the growth needs of different food crops such as wheat, corn and rice. China is the largest grain producer with 13 major grain producing areas. In 2019, China's grain sown area was $116.064 \times 10^{6}$ hectares and grain production reached $663.840 \times 10^{6}$ tons. In this paper, 31 provincial-level administrative regions were selected as the research unit, excluding Hong Kong, Macao and Taiwan.

2.2. Data sources and variable selection

Based on the existing research and data availability, this paper finally selected three variables, namely agricultural labor force, agricultural mechanization level and water resource endowment, to explore their impact on food production from three aspects: socio-economic development, agricultural technology progress, and natural resources. It should be noted that with the adjustment of China's industrial structure, the rapid development of secondary and tertiary industries increased off-farm employment with high income, resulting in a large-scale outflow of agricultural labor force (Liu et al. 2019; Qiu et al. 2020). Therefore, the agricultural labor force can be regarded as a socio-economic factor. All data of these variables were collected at the provincial and national levels from 2001 to 2019.

\subsubsection{Grain production}

As the foundation of food production, land is the core resource to ensure food security (Ge et al. 2018a; Wang et al. 2019b). According to Liu et al. (2018), this paper selected the grain 
sown area to measure grain production. The data from 2001 to 2019 were collected from the provincial annual data of the National Bureau of statistics ${ }^{1}$.

\subsubsection{Agricultural labor force}

Agricultural labor force is an indispensable factor in grain production (Long et al. 2016). Theoretically, the abundant agricultural labor force can meet the demand for large-scale production, thereby increasing food production capacity. Referring to the research of Huang and $\mathrm{Li}$ (2019), the employed persons in the primary industry were selected as the alternative index of agricultural labor force, and the data from 2001 to 2019 were obtained from the provincial annual data of the National Bureau of Statistics.

\subsubsection{Agricultural mechanization level}

Promoting agricultural mechanization is an important way to improve food production capacity (Li and Zhang 2021). According to Qiao (2017), the total power of agricultural machinery was selected to measure the mechanization level. The greater the value, the higher the mechanization level. Generally, food production has scale effect in areas with high level of agricultural mechanization. The data of total power of agricultural machinery from 2001 to 2019 were derived from the provincial annual data of the National Bureau of Statistics.

\subsubsection{Water resource endowment}

Food production consumes a large amount of water (Sun et al. 2019). According to Zhang et al. (2019), this paper used the gross amount of water resources to measure water resource endowment. The data from 2004 to 2019 were collected from the provincial annual data of the National Bureau of Statistics, and the data from 2001 to 2003 were obtained from the Provincial Statistical Yearbook (2002-2004). The missing data were supplemented by linear interpolation. The descriptive statistics of each variable were shown in Table 1.

\footnotetext{
${ }^{1}$ The website of the National Bureau of Statistics: https://data.stats.gov.cn/easyquery.htm?cn=E0103
} 


\begin{tabular}{ccccccc}
\hline Variables & Unit & Mean & S.D. $^{\mathrm{a}}$ & Maximum & Minimum & Number $^{\mathrm{b}}$ \\
\hline Grain & $10^{3}$ & 3575.062 & 2927.811 & 14338.100 & 46.520 & 589 \\
production & hectares & & & & & \\
Agricultural & & & & & & \\
labor force & $10^{4}$ people & 955.185 & 720.099 & 3482.500 & 37.090 & 589 \\
Agricultural & $10^{4}$ & & & & & \\
mechanization & kilowatt & 2785.462 & 2703.580 & 13353.020 & 93.970 & 589 \\
level & & & & & \\
Water resource & $10^{8}$ cubic & & & & & \\
endowment & metre & 885.755 & 946.380 & 4757.100 & 3.670 & \\
\hline
\end{tabular}

${ }^{a}$ represents standard deviation

${ }^{\mathrm{b}}$ represents number of samples

There were order-of-magnitude differences among the variables, which might bias the estimation results. Therefore, logarithms were taken for each variable before conducting the empirical analysis.

2.3. Methodology

2.3.1. Spatial autocorrelation analysis

This paper used spatial autocorrelation analysis to reveal the spatial dependence of grain production in each research unit, including global spatial autocorrelation and local spatial autocorrelation.

(1) Global spatial autocorrelation

Global spatial autocorrelation can measure the degree of agglomeration of grain production on the whole spatial scale, and determine whether regions with similar spatial location have similar attribute values. The global Moran's index (Moran 1950) is usually used as a measure, and the formula was as follows: 


$$
I=\frac{\sum_{\mathrm{i}=1}^{n} \sum_{\mathrm{j}=1}^{n} w_{i j}\left(x_{i}-\bar{x}\right)\left(x_{j}-\bar{x}\right)}{S^{2} \sum_{i=1}^{\mathrm{n}} \sum_{\mathrm{j}=1}^{\mathrm{n}} w_{i j}}
$$
where $S^{2}=\frac{1}{n} \sum_{i=1}^{n}\left(x_{i}-\bar{x}\right)^{2}$ is the sample variance; $\bar{x}=\frac{1}{n} \sum_{i=1}^{n} x_{i}$ is the sample mean; $x_{i}$ and

$x_{j}$ represent the grain sown area of province $i$ and province $j$, respectively; $w_{i j}$ is the spatial weight matrix using Rook neighbor relationship. If province $i$ and province $j$ have a common edge, then $w_{i j}$ is 1 , otherwise $w_{i j}$ is $0 ; I$ is the global Moran index with the value range of $[-1,1]$. $I>0$ means positive spatial autocorrelation, $\mathrm{I}<0$ means negative spatial autocorrelation, and $I=0$ means no spatial autocorrelation.

(2) Local spatial autocorrelation

As the complement to global spatial correlation, local spatial autocorrelation can reflect the local spatial clustering of grain production, reveal the spatial dependence between a geographic thing and its neighborhood. The local Moran's index (Anselin 1995) was as follows:

$$
I_{\mathrm{i}}=\frac{1}{S_{2}}\left(x_{i}-\bar{x}\right) \sum_{j=1}^{n} w_{i j}\left(x_{j}-\bar{x}\right)
$$

where $I_{i}$ is the local Moran index, $I_{i}>0$ means that the gap in grain sown area between province $i$ and neighboring provinces is small, i.e., high values are adjacent to high values and low values are adjacent to low values, and $I_{i}<0$ means that the gap in grain sown area between province $\mathrm{i}$ and neighboring provinces is large, i.e., high values are adjacent to low values; the remaining parameters are the same as in Eq.(1). The global and local Moran indices were calculated by GeoDa software (Anselin et al. 2014).

2.3.2. Geographically weighted regression

According to the first law of geography, the less the distance, the closer the relationship (Tobler 1970). The relationship between variables will vary with the change of geographic location, showing spatial non-stationarity. Based on this, this paper used the GWR model 
(Brunsdon et al. 1996; Fotheringham et al. 1998; Fotheringham et al. 2003) to measure the spatial heterogeneity. And the parameters were estimated by moving window regression to capture the spatial effects. The model was as follows:

$$
y_{i}=\beta_{0}\left(\mu_{i}, v_{i}\right)+\sum_{k=1}^{m} \beta_{k}\left(\mu_{i}, v_{i}\right) x_{i k}+\varepsilon_{i} \quad i=1,2, \cdots, n
$$

where $\left(\mu_{i}, v_{i}\right)$ is the coordinate of sample point $i ; x_{i k}$ is the $k t h$ explanatory variable of sample point $i$; $\beta_{k}$ is the regression coefficient of the $k t h$ explanatory variable; $\varepsilon_{i}$ is the stochastic error term; and $n$ is the number of sample points in the current local window.

$$
\beta_{k}\left(\mu_{i}, v_{i}\right) \text { can be estimated by Eq.(4). }
$$

$$
\hat{\beta}\left(\mu_{i}, v_{i}\right)=\left[X^{T} W\left(\mu_{i}, v_{i}\right) X\right]^{-1} X^{T} W\left(\mu_{i}, v_{i}\right) Y
$$

where $\mathrm{W}\left(\mu_{i}, v_{i}\right)$ is the spatial weight matrix calculated by the fixed bi-square kernel function and Euclidean distance, and the optimal bandwidth was selected according to the AICc criterion (Hurvich et al. 1998; Burnham et al. 2004). The GWR 4.0 software was used to implement the GWR model.

\section{Results}

3.1. Spatio-temporal evolution of grain production

\subsubsection{Interannual variation of grain production}

As shown in Fig. 1, China' 's grain sown area showed an overall upward trend, from $106.080 \times 10^{6}$ ha in 2001 to $116.064 \times 10^{6}$ ha in 2019 , with a total increase of $9.981 \times 10^{6}$ ha and an average annual growth rate of $0.501 \%$. It can be divided into four stages: the first stage was the rapid decline period from 2001 to 2003 , with an average annual growth rate of $-3.195 \%$, and the grain sown area reached its lowest point of $99.410 \times 10^{6}$ ha in 2003 . The second stage was the rapid growth period from 2004 to 2009, with an average annual growth rate of $1.647 \%$. After 2005, the growth rate increased year by year. The third stage was the stable rising period from 2010 to 2015, with an average annual growth rate of $1.269 \%$, At this stage, the grain sown 
area showed a linear growth trend, and the growth rate remained basically unchanged. The fourth stage was the slow declining period from 2016 to 2019, with an average annual decrease of $0.089 \%$, and the grain sown area reached the peak of $119.230 \times 10^{6}$ ha in 2016 . Since then, it once again entered the decline state. However, both the total amount and the rate of reduction were significantly lower than that in the first stage.

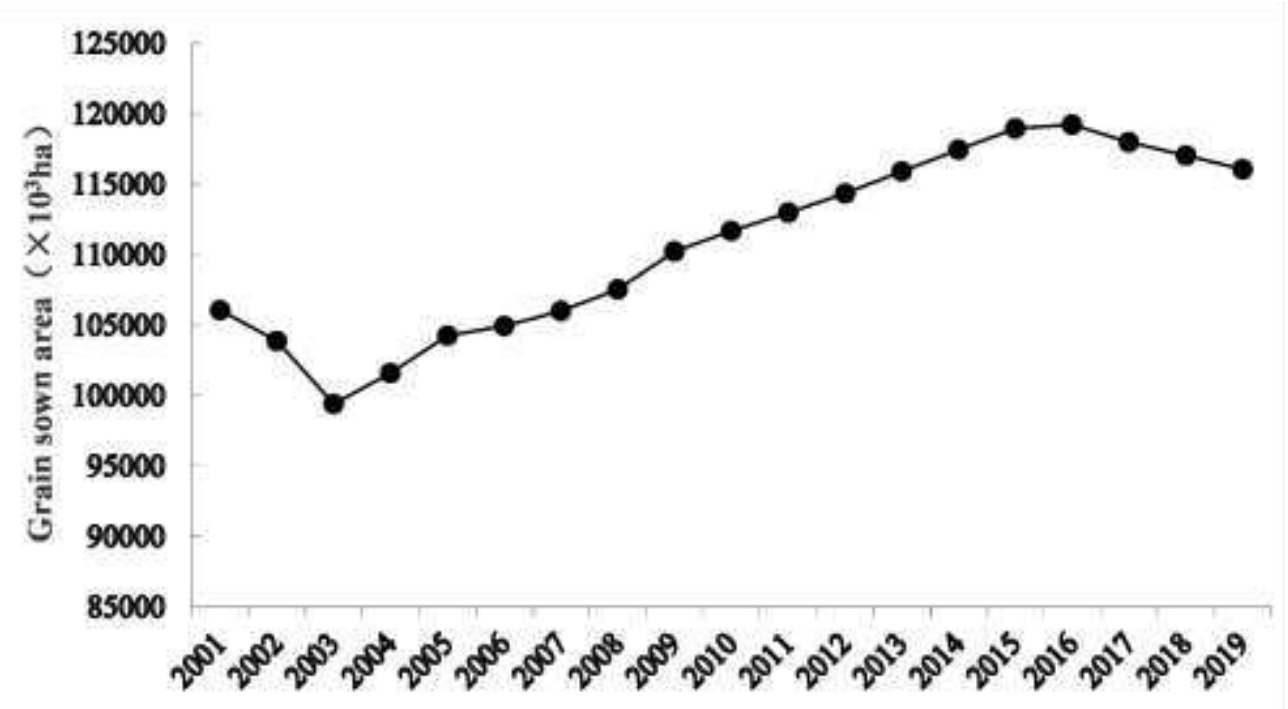

Fig. 1 Temporal trends of grain sown area in China

\subsubsection{Spatial variation of grain production}

Based on 31 provincial-level administrative regions, four time points of 2001, 2007, 2013 and 2019 were selected to analyze the spatial distribution of grain production in China, and the analysis results were shown in Fig. 2. 

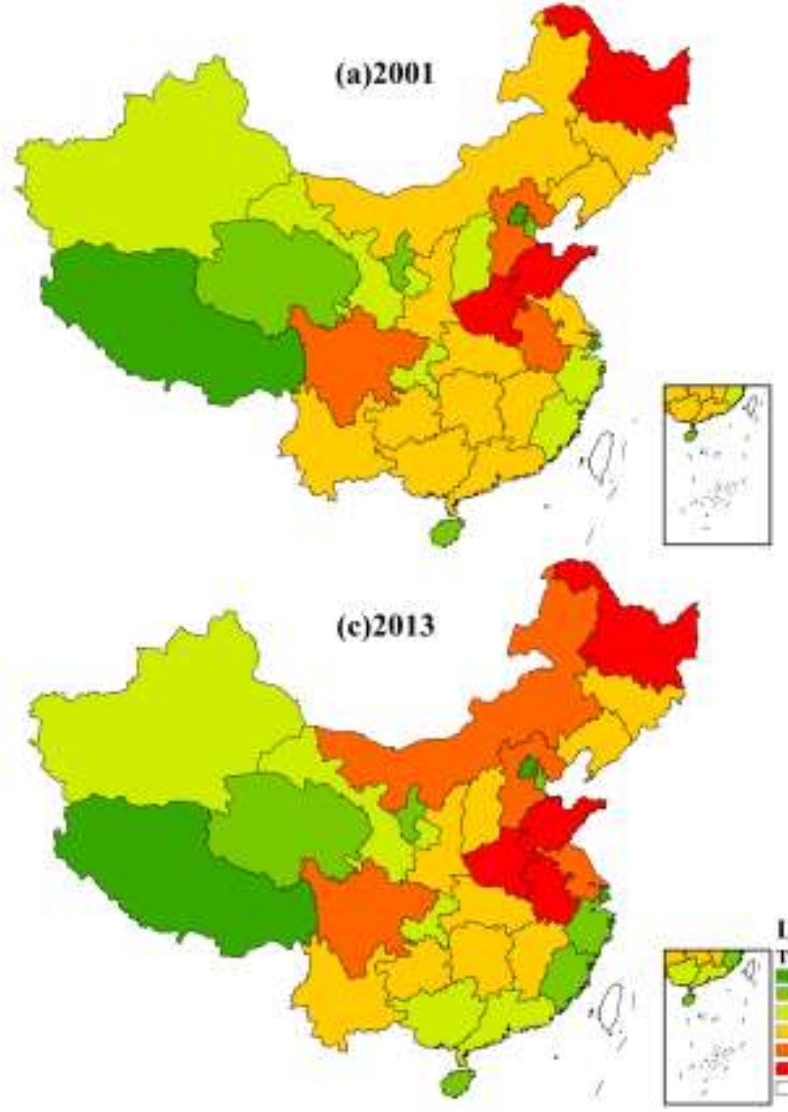

(c) 2013

Fig. 2 Spatial distribution of

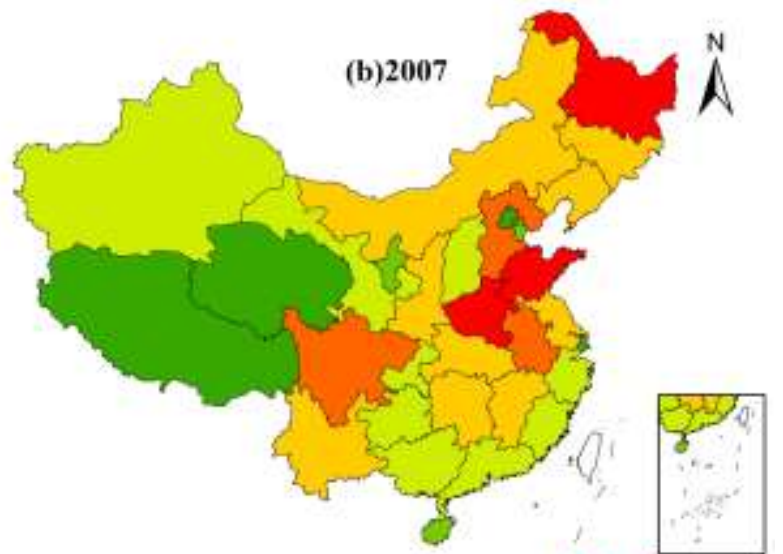

(d) 2019
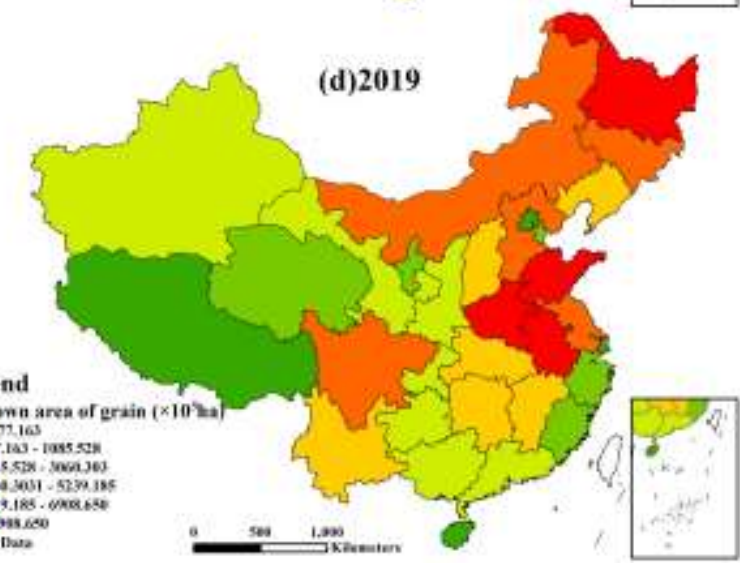

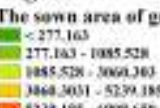

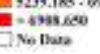

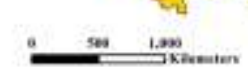

Legend

to 2019

The results showed that there were obvious spatial differences in China's grain sown area. Firstly, the grain sown area in the central-eastern region was significantly higher than that in the western region on a national scale, showing a spatial distribution characteristic of decreasing from east to west. In addition, the number of provinces with large grain sown area in the central and eastern regions increased throughout the whole study period. Similarly, the grain sown area in the north was significantly more than that in the south, and the number of provinces with large grain planting area in the north also increased over time, indicating that China's grain production regions have a spatial trend of moving northward and eastward. Secondly, based on the inter-provincial level, Heilongjiang, Shandong and Henan were the three provinces with the largest grain sown area, followed by Hebei, Anhui, Sichuan and other provinces who were major grain producing areas. Beijing, Shanghai, Tibet, Ningxia, Qinghai and other provinces were the provinces with the least grain sown area. In terms of changing trends, the grain sown area of Inner Mongolia, Jiangsu and Jilin showed an upward trend, while that in five provinces, 


\begin{tabular}{cccc}
\hline Year & Global Moran's I & Z-score & P-value \\
\hline 2001 & 0.205 & 2.039 & 0.041 \\
2007 & 0.224 & 2.251 & 0.024 \\
2013 & 0.243 & 2.447 & 0.014 \\
2019 & 0.270 & 2.703 & 0.007 \\
\hline
\end{tabular}
measure the local Moran index to investigate the local spatial agglomeration effect of grain

namely Zhejiang, Fujian, Guangdong, Guangxi and Hainan showed a downward trend. By contrast, the grain sown area of Guizhou showed certain fluctuation.

\subsubsection{Spatial clustering of grain production}

The global Moran indices of grain production in China from 2001 to 2019 were shown in Table 2. As can be seen, the global Moran indices of the four time points were $0.205,0.224$, 0.243 and 0.270 , respectively, and all of them were significant at the $5 \%$ level. That showed that there was a significant spatial positive autocorrelation of grain production, i.e., provinces with similar sown areas were spatially adjacent. In addition, the global Moran index showed an increasing trend, indicating that the spatial clustering effect of grain production was gradually increasing.

Based on the global spatial autocorrelation analysis, The software of Geoda was used to production, and ArcGIS 10.5 was used to visualize it (Fig. 3). 

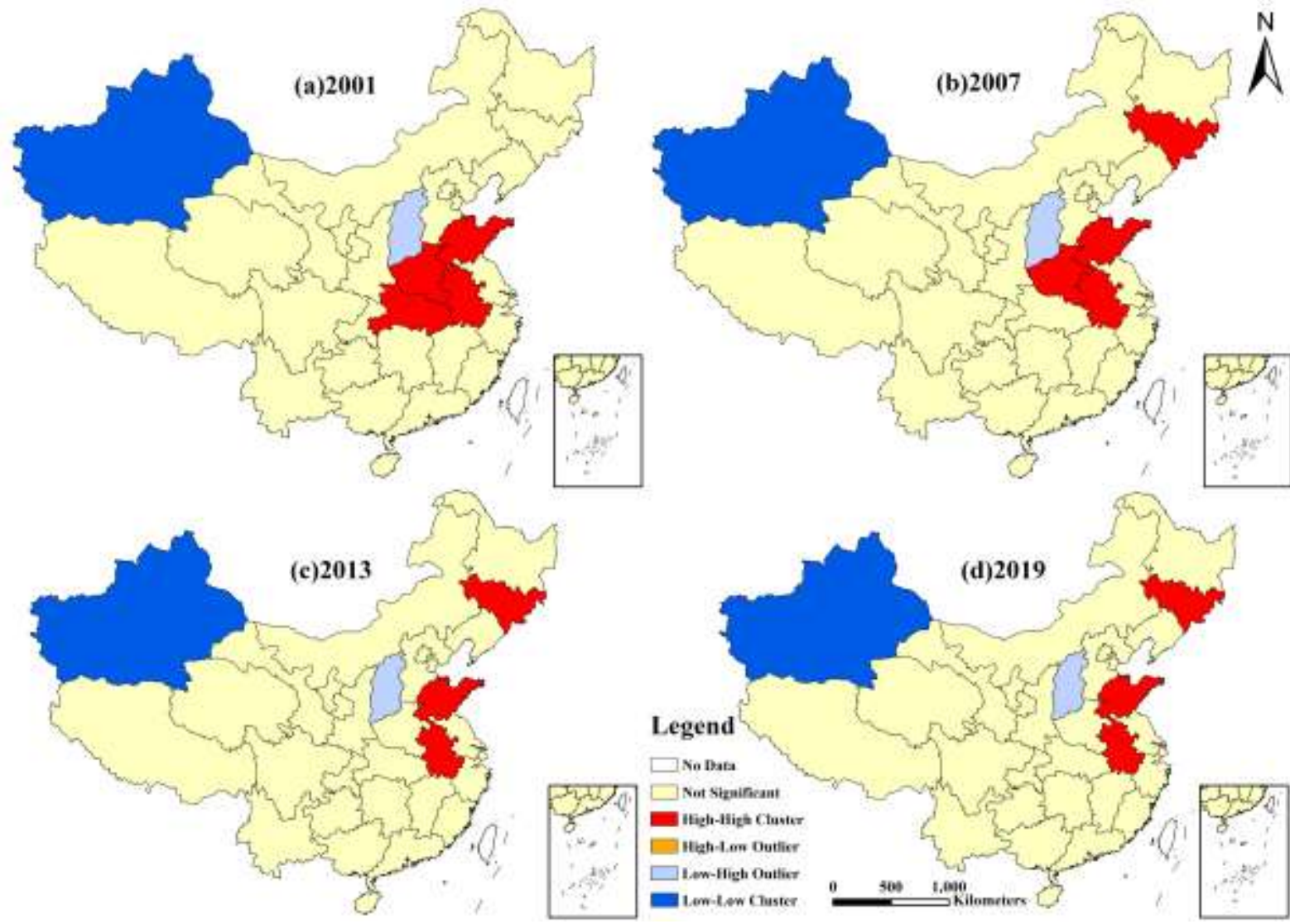

1.om-Low Cluster

Fig. 3 Spatial clustering effect of grain production in China from 2001 to 2019

The results showed that: firstly, the location of the high-high clusters in 2001 consist of four provinces - Shandong, Henan, Anhui and Hubei - and the low-high clusters were Shanxi, while Xinjiang was the low-low cluster; secondly, in 2007, the high-high clusters were Shandong, Jilin, Henan and Anhui provinces. Compared with 2001, their locations moved northward, while the low-high and low-low clusters did not change, and they were still Shanxi and Xinjiang; thirdly, the LISA cluster maps in 2013 and 2019 were the same, indicating that the local spatial distribution of grain production in China from 2013 to 2019 was basically stable without significant changes. Compared with the two time points of 2001 and 2007, the main differences were reflected in the fact that the high-high clusters were mainly composed of Shandong, Jilin and Anhui provinces, and the number decreased while the location shifted eastward and northward.

3.2. Analysis of factors influencing the grain production

\subsubsection{Model testing}


The GWR model was evaluated to test the reliability before empirical analysis. According to analysis results, the $\mathrm{R}^{2}$ and Adj- $\mathrm{R}^{2}$ of the GWR model were higher than those of the OLS model in four time points, and the values of $\mathrm{AIC}, \mathrm{AIC}_{\mathrm{C}}$, and RSS were smaller than those of the OLS model, indicating that the GWR model had better evaluation effects and could accurately reflect the influence of different factors on grain production ${ }^{2}$. Therefore, it was reasonable to select the GWR model for empirical analysis. It should be noted that the arithmetic mean of the bandwidths of the four time points was selected as the uniform optimal bandwidth, $2769.262 \mathrm{~km}$.

\subsubsection{Impact of agricultural labor force on grain production}

Table 3 reflected the coefficient of agricultural labor force. As can be seen, the sign of the regression coefficient was positive, and agricultural labor force was beneficial to increase grain area sown. The regression coefficient showed a slight upward trend between 2001 and 2007.

The minimum, lower quartile, median, mean, and upper quartile of the coefficients gradually decreased from 2007 to 2019, and the positive effect of agricultural labor force on grain production kept weakening.

Table 3 Coefficient distribution of agricultural labor force

\begin{tabular}{ccccccc}
\hline Year & Minimum & $\begin{array}{c}\text { Lower } \\
\text { quartile }\end{array}$ & Median & Mean & $\begin{array}{c}\text { Upper } \\
\text { quartile }\end{array}$ & Maximum \\
& & & & & \\
\hline 2001 & 0.253 & 0.615 & 0.780 & 0.749 & 0.903 & 0.961 \\
2007 & -0.010 & 0.682 & 0.860 & 0.774 & 0.906 & 0.992 \\
2013 & -0.035 & 0.217 & 0.532 & 0.500 & 0.748 & 1.048 \\
2019 & -0.121 & 0.064 & 0.316 & 0.287 & 0.484 & 0.775 \\
\hline
\end{tabular}

According to the spatial distribution of the estimated results (Fig. 4), the four time points showed obvious spatial differentiation characteristics. Specifically, the high values in 2001

\footnotetext{
${ }^{2}$ R2 and Adj-R2 are the goodness of fit and adjusted goodness of fit, respectively, and the larger the value means the better the fitting effect of the model; $\mathrm{AIC}$ and $\mathrm{AIC}_{\mathrm{C}}$ are the Akaike Information Criterion and the corrected Akaike Information Criterion, respectively; and smaller values are better; RSS indicates the residual sum of squares, and smaller values indicate more accurate estimation results.
} 
were mainly concentrated in Guangdong, Guangxi, Yunnan and other places, and the low value areas were Inner Mongolia, three provinces in Northeast China, indicating that overall spatial distribution was high in the southwest and low in the northeast; In 2007, the overall spatial pattern changed did not change significantly, the high value areas showed a slight increase, and the three provinces in northeast China were low value areas; In 2013 and 2019, the spatial pattern of high in the southwest and low in the northeast tended to be stable. The high value areas are Tibet, Yunnan, Sichuan and other provinces, and three provinces of Heilongjiang, Jilin and Liaoning had the smallest values. The coefficient gradually increased from northeast to southwest, showing a multilevel step distribution.

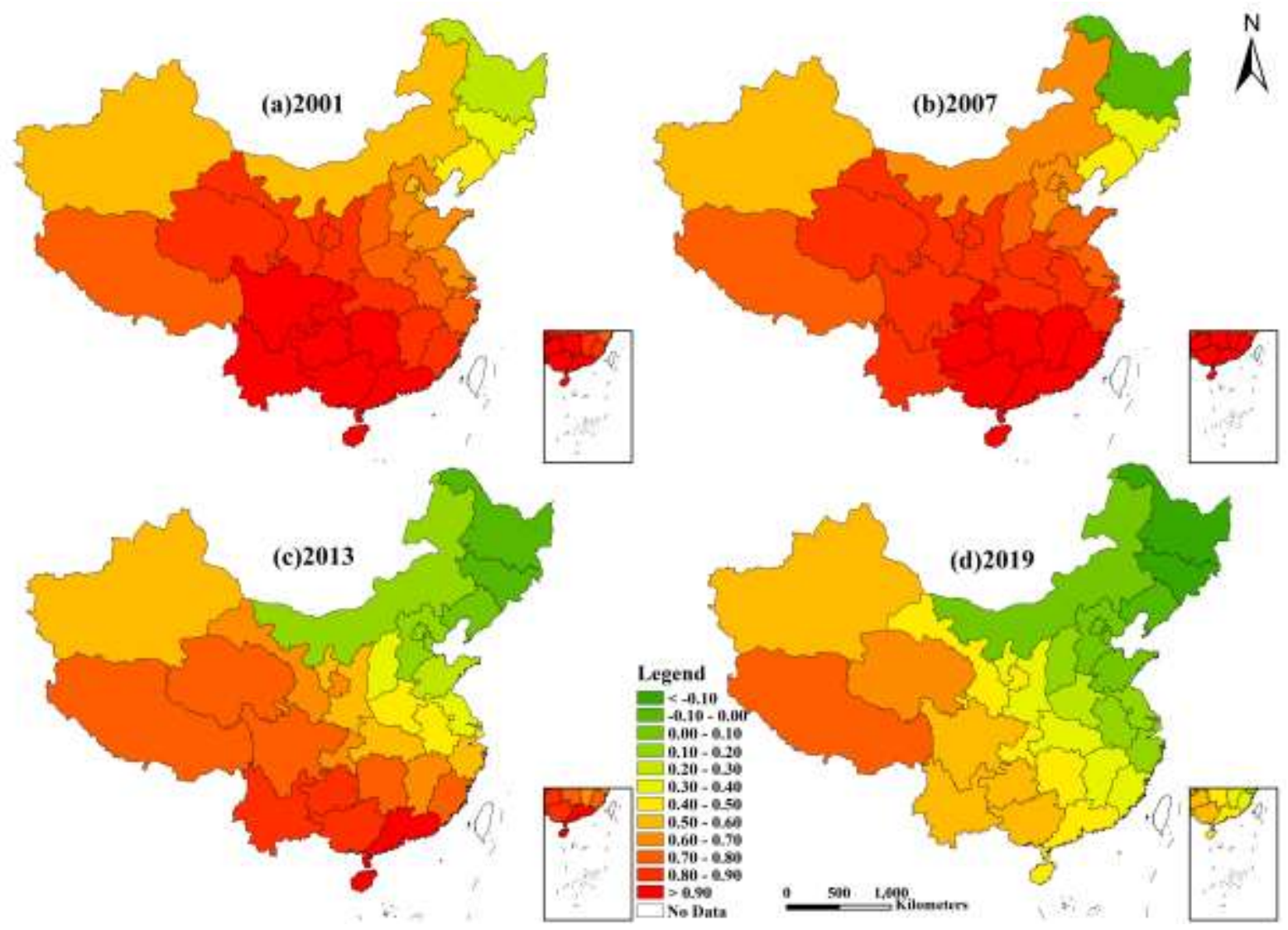

Fig. 4 Spatial distribution of estimated parameters of agricultural labor force

\subsubsection{Impact of agricultural mechanization on grain production}

Table 4 showed the coefficients of mechanization level in four time points. As can be seen from the table, the regression coefficients were all greater than 0 , and the minimum, lower quartile, median, mean and upper quartile gradually increased. The promotion of mechanization 
281 level on the grain production showed an upward trend.

Table 4 Coefficient distribution of mechanization level

\begin{tabular}{ccccccc}
\hline Year & Minimum & $\begin{array}{c}\text { Lower } \\
\text { quartile }\end{array}$ & Median & Mean & $\begin{array}{c}\text { Upper } \\
\text { quartile }\end{array}$ & Maximum \\
\hline 2001 & 0.078 & 0.140 & 0.213 & 0.236 & 0.321 & 0.623 \\
2007 & 0.196 & 0.249 & 0.276 & 0.333 & 0.380 & 0.895 \\
2013 & 0.203 & 0.409 & 0.561 & 0.564 & 0.751 & 0.834 \\
2019 & 0.497 & 0.752 & 0.854 & 0.878 & 1.041 & 1.153 \\
\hline
\end{tabular}

The spatial differences in coefficients of mechanization level were obvious (Fig. 5). In 2001, the high value areas were Xinjiang and Jilin, and the low value areas were mainly concentrated in Guangdong, Guangxi and Sichuan. The spatial distribution pattern of high in the northeast and low in the southwest began to appear. From 2007 to 2013, the high value areas further increased, mainly in the three provinces in Northeast China and Xinjiang, while the low value areas were still Guangxi, Yunnan and other places. The overall distribution characteristics of high in northeast and low in southwest tended to be stable. The spatial distribution pattern in 2019 was obvious. Inner Mongolia, three provinces in Northeast China and Hebei were high

291 value areas, while Yunnan, Sichuan and Tibet were low value areas. The coefficient decreased 292 from northeast to southwest, showing a multilevel step distribution. 


\begin{tabular}{ccccccc}
\hline Year & Minimum & Lower & Median & Mean & Upper & Maximum \\
& & quartile & & & & \\
\hline 2001 & -0.102 & -0.081 & -0.048 & 0.005 & 0.052 & 0.455 \\
2007 & -0.210 & -0.163 & -0.134 & -0.090 & -0.067 & 0.518 \\
2013 & -0.246 & -0.125 & -0.060 & -0.021 & 0.073 & 0.394 \\
\hline
\end{tabular}

Fig. 5 Spatial distribution of estimated parameters of agricultural mechanization

3.2.4. Impact of water resource endowment on grain production

Based on the regression coefficients of water resource endowment (Table 5), it can be seen that the sign of the coefficient was basically negative, indicating that water resource endowment was not conducive to increasing grain sowing area. The minimum, lower quartile, median, mean and upper quartile of regression coefficients showed a downward trend from 2001 to 2007. While, the median, mean and upper quartile increased first and then decreased, and the maximum continued to decline during the period 2007-2019.

Table 5 Coefficient distribution of water resource endowment

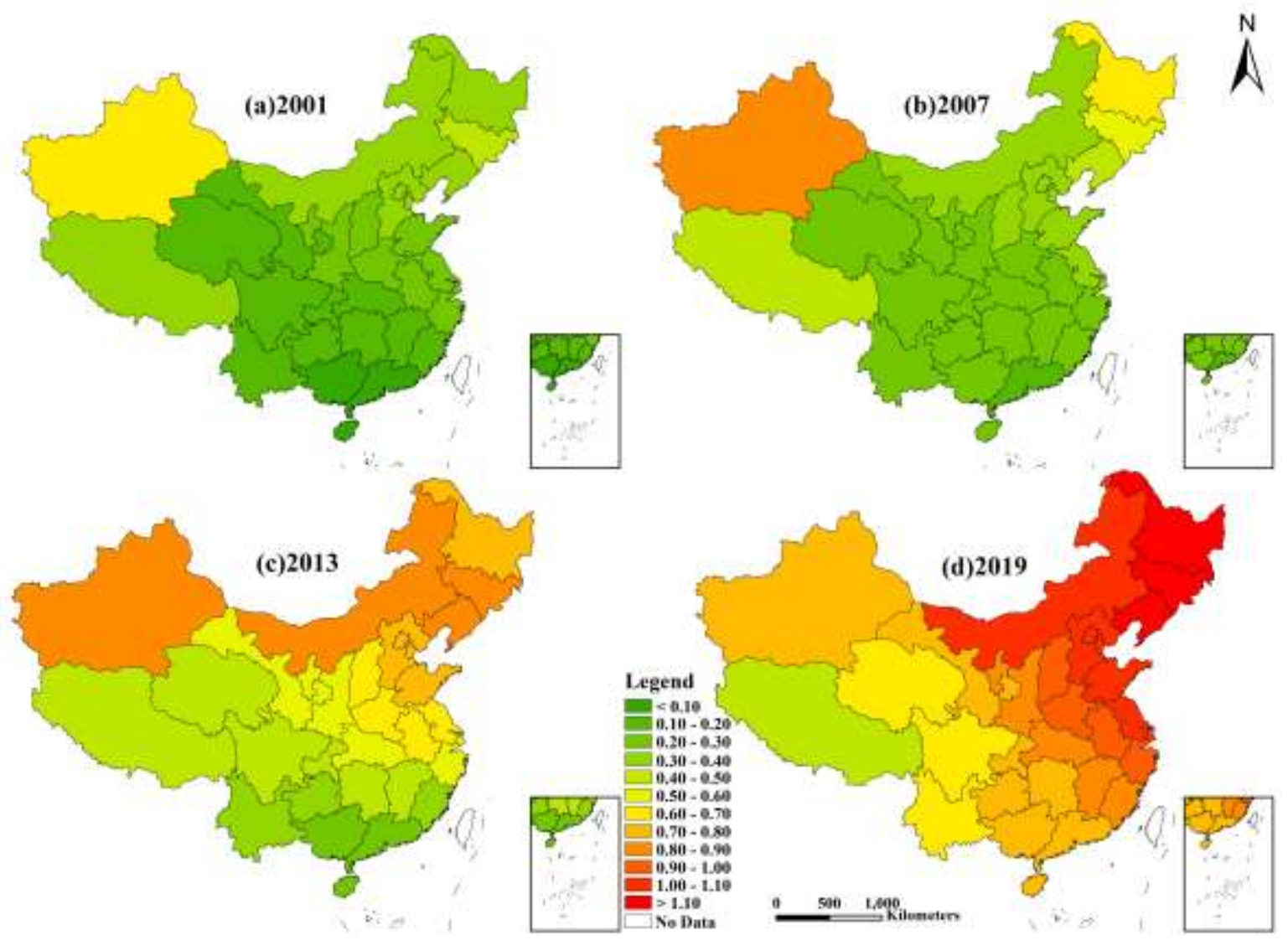




\begin{tabular}{lllllll}
\hline 2019 & -0.157 & -0.121 & -0.079 & -0.057 & -0.012 & 0.180 \\
\hline
\end{tabular}

The spatial distribution of coefficients of water resource endowment was shown in Fig. 6. It can be seen that the spatial pattern was high in the north and low in the south during the study period. Specifically, in 2001, the high value areas were mainly Inner Mongolia, Heilongjiang, Jilin and Liaoning provinces, and the low value areas were mainly Yunnan, Tibet and Guangxi provinces. The coefficient decreased from northeast to southwest. In 2007, provinces such as Yunnan, Guangxi and Guangdong were low value areas, and high value areas were Heilongjiang and Jilin, indicating that the spatial pattern of high in the north and low in the south tended to be stable. From 2013 to 2019, the spatial differences became more and more obvious. The three provinces in northeast China and Inner Mongolia were always high value areas and decreased southward, while Tibet, Yunnan and Guangdong were always low value areas.

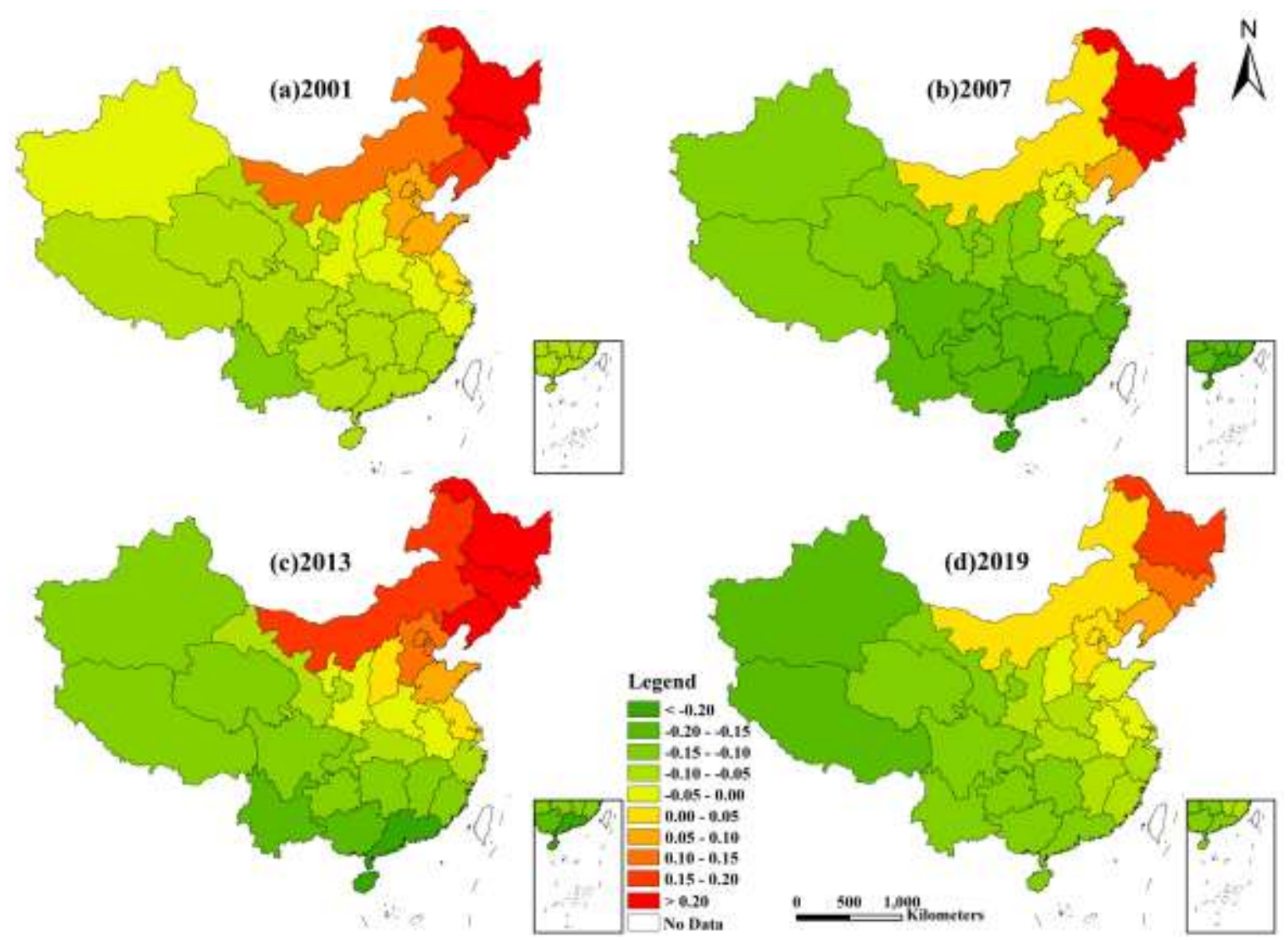

Fig. 6 Spatial distribution of estimated parameters of water resource endowment

\section{Discussion}


The grain production in China was affected by factors such as agricultural labor force, agricultural mechanization level and water resource endowment, showing different characteristics in different regions. Specifically, the increase of agricultural labor force was beneficial to the expansion of grain sown area. However, the positive contribution of agricultural labor force to grain production became smaller and smaller, which is consistent with Ge et al. (2018b). The reason was that young farmers moved to the secondary and tertiary industries to seek higher income (Benjamin 1992; De Brauw et al. 2002; Wang et al. 2007), leading to insufficient labor supply and rising labor cost (Zhang et al. 2011). Finally, the decline of human capital of surplus labor had a negative impact on food production. Meanwhile, the use of agricultural machinery made up for the loss of food production caused by labor shortages (Ji et al. 2017a). Compared with other regions, agricultural machinery in major grain producing areas can replace manpower to achieve large-scale operation due to the flat and contiguous land, reducing costs and improving food production efficiency. Therefore, the major grain producing areas became areas with high values of mechanization coefficients and low values of labor force coefficients. The average of coefficients of water resource endowment changed from positive to negative, indicating that the impact of water resources on grain production changed from promotion to inhibition during the study period. The coefficients in the south were negative while those in the north were positive, showing that there was an obvious spatial mismatch between grain production and water resource endowment. The reason was that the northern regions paid more attention to food production. Although water resources were relatively insufficient, it can still meet the water demand for crop growth by overexploiting groundwater (Kuang et al. 2015), thereby increasing the grain sown areas. Comparatively speaking, the rapid growth of industry and service sector in the southern regions occupied a large amount of agricultural water, resulting in the unmet water demand for grain production. So, agricultural production made concessions for economic development ( $\mathrm{Li}$ and $\mathrm{Li} 2014$ ). 
Based on this, this paper proposed the following policy recommendations:

Firstly, with the advancement of urbanization and industrialization, it became a common phenomenon that the prime-working-age labor force in rural areas continued to migrate to cities (Cai 2018). The aging and feminization of the rural labor force directly reduced the human

capital and had a negative impact on food production. However, the realization of agricultural modernization can not lack farmers. Therefore, relevant departments should establish and improve the training system of professional farmers and enhance the overall quality of labor force. Furthermore, preferential policies should be formulated to encourage working-age labor force to engage in agricultural production.

Secondly, agricultural mechanization played a significant role in improving food production capacity. However, farmers can not afford the agricultural machinery, they mainly purchased agricultural mechanization services to meet the machinery demand for food production (Yang et al. 2013; Zhang et al. 2017). Therefore, the government should pay attention to the important role of agricultural mechanization in food production. Especially for the major grain producing areas, relevant departments should strengthen the subsidy and support for agricultural machinery, promote the renewal and popularization of agricultural machinery so as to reduce labor intensity and planting cost, improve production efficiency and ensure national food security.

Thirdly, facing the realistic dilemma of more land and less water, China is no longer suitable for traditional irrigation methods (Peng 2011). In order to meet the water demand for grain production, the Chinese government and farmers must place a high value on the protection and conservation of water resources and resolutely resist water pollution. Especially for the major grain producing areas in the north with relatively insufficient water resources, new irrigation technologies should be adopted to reasonably allocate water resources according to the growth characteristics of different crops, and improve the use efficiency of agricultural water. The 
southern regions should improve the technology of sewage purification, return the water used by the secondary and tertiary industries to agriculture, and increase grain production capacity.

\section{Conclusion}

This paper analyzed the spatio-temporal evolution characteristics of grain production in China from 2001-2019 through global and local Moran indices, and further explored the influencing factors by using geographically weighted regression. The main conclusions were as follows:

(1) The average annual growth rate of grain sown area in China was $0.501 \%$. It reached a peak of $119.230 \times 10^{6}$ ha in 2016 , and its development process can be divided into four stages, namely rapid decline (2001-2003), rapid growth (2004-2009), steady rise (2010-2015), and slow decline (2016-2019).

(2) Grain production in China showed significant positive spatial autocorrelation in general, and the degree of correlation gradually strengthened; local areas also showed positive spatial autocorrelation. The local spatial agglomeration effect decreased from 2001 to 2007. After 2013, the local spatial distribution of grain production was basically stable.

(3) China's grain production was affected by many factors. Specifically, the positive influence of agricultural labor force on grain production was decreasing year by year; the coefficient of water resource endowment was basically negative with obvious differences among provinces, showing the spatial distribution pattern of high in the north and low in the south; the positive impact of agricultural mechanization level on grain production gradually increased, and the overall spatial distribution pattern was high in the northeast and low in the southwest.

Of course, this paper also had some shortcomings. We only analyzed the nationwide grain production and did not subdivide it into different grain crops to explore spatio-temporal variations and influencing factors respectively, nor did we consider the relationship between 
grain crops, because the sown area of one grain crop may increase with another. We will explore the above issues in future research.

\section{Funding}

This study benefited from joint financial support by the Programs of National Natural Science Foundation of China (No.41602336), China Postdoctoral Science Foundation (No.2017T100773), and Shaanxi Provincial Natural Science Foundation (No. 2020JM-170).

\section{Author contributions}

Shaoting Li and Daojun Zhang conceived the study; Shaoting Li proposed the methodology, and edited the manuscript; Chao Yang, Yuan Xie and Shaoting Li collected and analyzed the data; All authors have approved the final manuscript.

\section{Data availability}

Data are available from the first author (Shaoting Li) upon a reasonable request.

Acknowledgements Great thanks to the anonymous referees for their helpful suggestions and corrections.

\section{Declarations}

\section{Ethics approval and consent to participate Not applicable.}

Consent for publication Not applicable.

Competing interests The authors declare no competing interests.

\section{References}

Anselin L (1995) Local indicators of spatial association-LISA. Geographical analysis 27, 93-115. https://doi.org/10.1111/j.1538-4632.1995.tb00338.x

Anselin L, Rey SJ (2014): Modern spatial econometrics in practice: A guide to GeoDa, GeoDaSpace and PySAL. GeoDa Press LLC

Benjamin D (1992) Household composition, labor markets, and labor demand: testing for separation in agricultural household models. Econometrica: Journal of the Econometric Society, 287-322. https://doi.org/10.2307/2951598

Brunsdon C, Fotheringham AS, Charlton ME (1996) Geographically weighted regression: a method for exploring 
spatial nonstationarity. Geographical analysis 28, 281-298. https://doi.org/10.1111/j.15384632.1996.tb00936.x

Burnham KP, Anderson DR (2004) Multimodel inference: understanding AIC and BIC in model selection. Sociological methods \& research 33, 261-304. https://doi.org/10.1177/0049124104268644

Cai F (2018) The Great Exodus How agricultural surplus laborers have been transferred and reallocated in China's reform period? China Agricultural Economic Review 10, 3-15. https://doi.org/10.1108/caer-10-20170178

Chen J (2007) Rapid urbanization in China: A real challenge to soil protection and food security. Catena 69, 1-15. https://doi.org/10.1016/j.catena.2006.04.019

Chen Y, Wen X, Wang B, Nie P (2017) Agricultural pollution and regulation: How to subsidize agriculture? J. Clean Prod. 164, 258-264. https://doi.org/10.1016/j.jclepro.2017.06.216

De Brauw A, Huang J, Rozelle S, Zhang L, Zhang Y (2002) The evolution of China's rural labor markets during the reforms. J. Comp. Econ. 30, 329-353. https://doi.org/10.1006/jcec.2002.1778

Du XD, Jin XB, Yang XL, Yang XH, Xiang XM, Zhou YK (2015) Spatial-temporal pattern changes of main agriculture natural disasters in China during 1990-2011. J. Geogr. Sci. 25, 387-398. https://doi.org/10.1007/s11442-015-1175-x

Fotheringham AS, Charlton ME, Brunsdon C (1998) Geographically weighted regression: a natural evolution of the expansion method for spatial data analysis. Environment and planning A 30, 1905-1927. https://doi.org/10.1068/a301905

Ge DZ, Long HL, Zhang YG, Ma L, Li TT (2018a) Farmland transition and its influences on grain production in China. Land Use Policy 70, 94-105. https://doi.org/10.1016/j.landusepol.2017.10.010

Ge DZ, Long HL, Zhang YN, Tu SS (2018b) Analysis of the coupled relationship between grain yields and agricultural labor changes in China. J. Geogr. Sci. 28, 93-108. https://doi.org/10.1007/s11442-018-14615

Goodwin BK, Mishra AK (2005) Another look at decoupling: additional evidence on the production effects of direct payments. Am. J. Agr. Econ. 87, 1200-1210.

Guo JH, Liu XJ, Zhang Y, Shen JL, Han WX, Zhang WF, Christie P, Goulding KWT, Vitousek PM, Zhang FS (2010) Significant Acidification in Major Chinese Croplands. Science 327, 1008-1010. https://doi.org/10.1126/science. 1182570

Holst R, Yu XH, Grun C (2013) Climate Change, Risk and Grain Yields in China. J. Integr. Agric. 12, 1279-1291. 
https://doi.org/10.1016/s2095-3119(13)60435-9

Huang JK, Wang XB, Rozelle S (2013) The subsidization of farming households in China's agriculture. Food Policy 41, 124-132. https://doi.org/10.1016/j.foodpol.2013.04.011

Huang JK, Ding JP (2016) Institutional innovation and policy support to facilitate small-scale farming transformation in China. Agric. Econ. 47, 227-237. https://doi.org/10.1111/agec.12309

Huang JK, Yang GL (2017) Understanding recent challenges and new food policy in China. Glob. Food Secur.Agric.Policy 12, 119-126. https://doi.org/10.1016/j.gfs.2016.10.002

Huang ML, Li XY (2019) The impacts of rural labor price rising on crop structure among provinces. Economic Geography 39, 172-182. (In Chinese) https://doi.org/10.15957/j.cnki.jjdl.2019.06.019

Hurvich CM, Simonoff JS, Tsai CL (1998) Smoothing parameter selection in nonparametric regression using an improved Akaike information criterion. Journal of the Royal Statistical Society: Series B (Statistical Methodology) 60, 271-293. https://doi.org/10.1111/1467-9868.00125

Ji C, Guo HD, Jin SQ, Yang J (2017a) Outsourcing Agricultural Production: Evidence from Rice Farmers in Zhejiang Province. Plos One 12, 16. https://doi.org/10.1371/journal.pone.0170861

Ji Y, Hu X, Zhu J, Zhong F (2017b) Demographic change and its impact on farmers' field production decisions. China Economic Review 43, 64-71. https://doi.org/10.1016/j.chieco.2017.01.006

Jiao XQ, Lyu Y, Wu XB, Li HG, Cheng LY, Zhang CC, Yuan LX, Jiang RF, Jiang BW, Rengel Z, Zhang FS, Davies WJ, Shen JB (2016) Grain production versus resource and environmental costs: towards increasing sustainability of nutrient use in China. J. Exp. Bot. 67, 4935-4949. https://doi.org/10.1093/jxb/erw282

Jiao XQ, He G, Cui ZL, Shen JB, Zhang FS (2018) Agri-environment policy for grain production in China: toward sustainable intensification. China Agricultural Economic Review 10, 78-92. https://doi.org/10.1108/caer10-2017-0201

Kuang W, Hu YJ, Dai XQ, Song XY (2015) Investigation of changes in water resources and grain production in China: changing patterns and uncertainties. Theor. Appl. Climatol. 122, 557-565. https://doi.org/10.1007/s00704-014-1315-8

Li HJ, Liu ZJ, Zheng L, Lei YP (2011) Resilience analysis for agricultural systems of North China Plain based on a dynamic system model. Sci. Agric. 68, 8-17. https://doi.org/10.1590/s0103-90162011000100002

Li JM, Li ZH (2014) Physical limitations and challenges to Grain Security in China. Food Security 6, 159-167. https://doi.org/10.1007/s12571-013-0326-0

Li TT, Long HL, Zhang YN, Tu SS, Ge DZ, Li YR, Hu BQ (2017) Analysis of the spatial mismatch of grain 
production and farmland resources in China based on the potential crop rotation system. Land Use Policy 60, 26-36. https://doi.org/10.1016/j.landusepol.2016.10.013

Li WJ, Zhang PC (2021) Relationship and integrated development of low-carbon economy, food safety, and agricultural mechanization. Environ. Sci. Pollut. Res., 11. https://doi.org/10.1007/s11356-021-15465-2

Liu JC, Xu ZG, Zheng QF, Hua LL (2019) Is the feminization of labor harmful to agricultural production? The decision-making and production control perspective. J. Integr. Agric. 18, 1392-1401. https://doi.org/10.1016/s2095-3119(19)62649-3

Liu XW, Chen BM (2007) Efficiency and sustainability analysis of grain production in Jiangsu and Shaanxi Provinces of China. J. Clean Prod. 15, 313-322. https://doi.org/10.1016/j.jclepro.2005.07.003

Liu Y, Wang CG, Tang Z, Nan ZB (2018) Will farmland transfer reduce grain acreage? Evidence from Gansu province, China. China Agricultural Economic Review 10, 277-292. https://doi.org/10.1108/caer-042017-0072

Liu Z, Liu L (2016) Characteristics and driving factors of rural livelihood transition in the east coastal region of China: A case study of suburban Shanghai. Journal of Rural Studies 43, 145-158. https://doi.org/10.1016/j.jrurstud.2015.12.008

Long H, Qu Y (2018) Land use transitions and land management: A mutual feedback perspective. Land Use Policy 74, 111-120. https://doi.org/10.1016/j.landusepol.2017.03.021

Long HL, Tu SS, Ge DZ, Li TT, Liu YS (2016) The allocation and management of critical resources in rural China under restructuring: Problems and prospects. Journal of Rural Studies 47, 392-412. https://doi.org/10.1016/j.jrurstud.2016.03.011

Lu YL, Jenkins A, Ferrier RC, Bailey M, Gordon IJ, Song S, Huang JK, Jia SF, Zhang FS, Liu XJ, Feng ZZ, Zhang ZB (2015) Addressing China's grand challenge of achieving food security while ensuring environmental sustainability. Sci. Adv. 1, 5. https://doi.org/10.1126/sciadv.1400039

McMillen DP (2004) Geographically weighted regression: The analysis of spatially varying relationships. Am. J. Agr. Econ. 86, 554-556. https://doi.org/10.1111/j.0002-9092.2004.600_2.x

Moran PA (1950) Notes on continuous stochastic phenomena. Biometrika 37, 17-23. https://doi.org/10.1093/biomet/37.1-2.17

Niu YN, Xie GD, Xiao Y, Liu JY, Wang YY, Luo Q, Zou HX, Gan S, Qin KY, Huang MD (2021) Spatiotemporal Patterns and Determinants of Grain Self-Sufficiency in China. Foods 10, 27. https://doi.org/10.3390/foods 10040747 
Peng SQ (2011) Water resources strategy and agricultural development in China. J. Exp. Bot. 62, 1709-1713. https://doi.org/10.1093/jxb/err049

Qi X, Dang H (2018) Addressing the dual challenges of food security and environmental sustainability during rural livelihood transitions in China. Land use policy 77, 199-208. https://doi.org/10.1016/j.landusepol.2018.05.047

Qiao FB (2017) Increasing wage, mechanization, and agriculture production in China. China Economic Review 46, 249-260. https://doi.org/10.1016/j.chieco.2017.10.002

Qin H (2010) Rural-to-Urban Labor Migration, Household Livelihoods, and the Rural Environment in Chongqing Municipality, Southwest China. Human Ecology 38, 675-690. https://doi.org/10.1007/s10745-010-9353$\mathrm{Z}$

Qiu TW, Choy STB, Li SP, He QY, Luo BL (2020) Does land renting-in reduce grain production? Evidence from rural China. Land Use Policy 90, 10. https://doi.org/10.1016/j.landusepol.2019.104311

Rozelle S, Taylor JE, DeBrauw A (1999) Migration, remittances, and agricultural productivity in China. American Economic Review 89, 287-291. https://doi.org/10.1257/aer.89.2.287

Sun SK, Yin YL, Wu PT, Wang YB, Luan XB, Li C (2019) Geographical Evolution of Agricultural Production in China and Its Effects on Water Stress, Economy, and the Environment: The Virtual Water Perspective. Water Resour. Res. 55, 4014-4029. https://doi.org/10.1029/2018wr023379

Tobler WR (1970) A computer movie simulating urban growth in the Detroit region. Economic geography 46, 234240. https://doi.org/10.2307/143141

Wang HL, He P, Shen CY, Wu ZN (2019a) Effect of irrigation amount and fertilization on agriculture non-point source pollution in the paddy field. Environ. Sci. Pollut. Res. 26, 10363-10373. https://doi.org/10.1007/s11356-019-04375-z

Wang JM, Xiao HB (2013) The nature and prospect of grain production in China in the past eight years. Issues in Agricultural Economy 34, 22-31. (In Chinese with English abstract). https://doi.org/10.13246/j.cnki.iae.2013.02.005

Wang Q, Qiu JJ, Yu J (2019b) Impact of farmland characteristics on grain costs and benefits in the North China Plain. Land Use Policy 80, 142-149. https://doi.org/10.1016/j.landusepol.2018.10.003

Wang X, Thomas H, Thomas G (2007) Labor allocation in transition: Evidence from Chinese rural households. China Economic Review 18, 287-308. https://doi.org/10.1016/j.chieco.2007.02.004

Xu SW, Wu JZ, Song W, Li ZQ, Li ZM, Kong FT (2013) Spatial-Temporal Changes in Grain Production, 

https://doi.org/10.1016/s2095-3119(13)60236-1

Yang J, Huang ZH, Zhang XB, Reardon T (2013) The rapid rise of cross-regional agricultural mechanization services in China. Am. J. Agr. Econ. 95, 1245-1251. https://doi.org/10.1093/ajae/aat027

Yi F, Sun D, Zhou Y (2015) Grain subsidy, liquidity constraints and food security-Impact of the grain subsidy

Yi FJ, McCarl B (2018) Increasing the effectiveness of the Chinese grain subsidy: a quantitative analysis. China Agricultural Economic Review 10, 538-557. https://doi.org/10.1108/caer-08-2016-0136

Yin N, Wang YP (2017) Impacts of Rural Labor Resource Change on the Technical Efficiency of Crop Production in China. Agriculture-Basel 7, 12. https://doi.org/10.3390/agriculture7030026

Zhang DH, Wang HQ, Lou S, Zhong S (2021) Research on grain production efficiency in China's main grain producing areas from the perspective of financial support. Plos One 16, 16. https://doi.org/10.1371/journal.pone.0247610

Zhang FS, Chen XP, Vitousek P (2013) An experiment for the world. Nature 497, 33-35. https://doi.org/10.1038/497033a

Zhang X, Yang J, Wang S (2011) China has reached the Lewis turning point. China Economic Review 22, 542 554. https://doi.org/10.1016/j.chieco.2011.07.002

Zhang X, Yang J, Thomas R (2017) Mechanization outsourcing clusters and division of labor in Chinese agriculture. China Economic Review 43, 184-195. https://doi.org/10.1016/j.chieco.2017.01.012

Zhang X, Dong QJ, Costa V, Wang XX (2019) A hierarchical Bayesian model for decomposing the impacts of human activities and climate change on water resources in China. Sci. Total Environ. 665, 836-847. https://doi.org/10.1016/j.scitotenv.2019.02.189

Zhao Y (1999) Labor migration and earnings differences: the case of rural China. Economic Development and Cultural Change 47, 767-782. https://doi.org/10.1086/452431 